Revista de Estudios Histórico-Jurídicos

[Sección historia del derecho patrio]

XLI (Valparaíso, Chile, 2019)

[pp. 399 - 413]

\title{
EL PRIMER REGISTRO CHILENO SOBRE HIPOTECAS, CENSOS Y NAVES REGULADO EN EL REGLAMENTO DE 20 DE MAYO DE 1848
}

[The first chilean mortgages, censuses and ships record implemented by the Regulation of 20 may 1848]

\author{
Santiago Zárate GonZÁlez* \\ Universidad Central de Chile
}

\section{RESUMEN}

Rescatado por el autor del presente trabajo, el Reglamento sobre hipotecas, censos y naves de 20 de mayo de 1848 , resulta ser una pieza clave en el desarrollo del sistema de registro inmobiliario que Chile adoptará en el futuro Reglamento para la oficina del registro conservatorio de bienes raíces de 24 de junio de 1857. Estudiar por tanto las fuentes del sistema español de registración, las leyes patrias sobre prelación de créditos de 1845 y 1854, además del Reglamento sobre hipotecas, censos y naves de 20 de mayo, es de gran relevancia para la reconstrucción de la Historia del registro inmobiliario en Chile.

Palabras clave

Leyes - prelación - créditos - registro - hipotecas - reglamento.
Abstract

Rescued by the author of this work, the Regulation on mortgages, censuses and ships of May 20,1848, turns out to be a key piece in the development of the real estate registration system that Chile will adopt in the future Regulation for the office of the conservatory registry of real estate of June 24, 1857. To study therefore the sources of the Spanish system of registration, the national laws on priority of credits of 1845 and 1854, besides the Regulation on mortgages, censuses and ships of May 20, is of great importance for the reconstruction of the History of the real estate registry in Chile.

\footnotetext{
KeYwords

Acts - Priority - Credits - Registration - Mortgages - Regulation.
}

RECIBIDO el 18 de noviembre de 2018 y ACEPTADO el 30 de abril de 2019

* Docente jornada de la Universidad Central de Chile, Doctor en Derecho por la Pontificia Universidad Católica de Valparaíso, abogado y licenciado en Derecho de la Pontificia Universidad Católica de Chile. Postdoctorado en la Universidad Carlos III de Madrid. Dirección postal: Lord Cochrane 417-A, Santiago de Chile. Dirección electrónica: santiago.zarate@ucentral.cl 


\section{INTRODUCCIÓN}

En los albores de la década de 1840, los comerciantes de Valparaíso hicieron presión sobre el Congreso Nacional para que se trabajara en una legislación hipotecaria propia, tendiente a dar soluciones concretas al problema siempre presente de las quiebras de empresas, y a las hipotecas fantasmas constituidas en instrumentos privados, que aparecían mágicamente en los juicios de quiebra con concurso de acreedores. Urgía por tanto una nueva regulación a lo que ellos denominaban el sistema hipotecario ${ }^{1}$. En efecto, pues la idea principal de aquellos comerciantes y políticos influyentes de la época fue siempre remplazar las Ordenanzas del Consulado de Bilbao $^{2}$ por las normas del Código de Comercio francés de $1807^{3}$, por el Código de Comercio español de 1829, y sobre todo por la ley de quiebras francesa de 28 de mayo de 1838 que modificó al Código de Comercio francés de $1807^{4}$.

Desde antes de 1842, hubo un número considerable de quiebras en Valparaíso, y en los tribunales se admitía la presentación de escrituras conteniendo hipotecas sin su anotación o registro, lo que causaba graves inconvenientes y perjuicios a los acreedores hipotecarios, dejándolos en muy mal pie frente al resto de los miembros del concurso.

De hecho, una norma de la Partida $V^{5}$, que se creía derogada por la Real Pragmática de $1768^{6}$, se invocó por algunos acreedores perjudicados en apoyo de sus créditos, y los tribunales fallaron los pleitos conforme a ella. Es decir, bastaba un documento escrito (privado por tanto) suscrito ante tres testigos, para probar que allí existía un peño. Esta ley le atribuía por tanto valor de escritura pública a estos documentos, tal como se señala en el comentario de esta norma, "porque teniendo este documento fuerza de escritura pública [sin serlo], es aplicable la regla prior es tempore, potior est iure" [primero en el tiempo, primero en el derecho -hoy principio de prioridad registral-]. De este modo, llegó a suceder que la hipoteca convencional, general o especial, que constaba de simple escritura firmada por el deudor ante tres testigos (instrumento desprovisto de toda autenticidad), era preferida en los concursos con respecto a aquella constituida por instrumento

${ }^{1}$ Letelier, Valentín, Sesiones de los cuerpos legislativos de la república de Chile 1811-1845, Cámara de Senadores (Santiago, 1908), XXXV, p. 256.

${ }^{2}$ Ordenanzas del Consulado de Bilbao, en Los códigos españoles (Madrid, 1851), XII.

${ }^{3}$ Code de Commerce français (Paris, 1807), I. También Código de Comercio español (Madrid, 1829).

${ }^{4}$ Véase referencia a la Ley de quiebras y bancarrota francesa de 28 de mayo de 1838 , en Carbonell O’Brien, Esteban, Banca y suspensión de pagos. Mecanismos alternativos de reingeniería legal (Lima, 2007).

${ }^{5}$ Part. 5, 13, 31: "Como aquel que muestra carta de escribano público, en que empeña alguna cosa, ha mayor derecho en ella, que otro que mostrase otra escritura o prueba de testigos". Véase Las Siete Partidas de Alfonso X, en Los códigos españoles concordados y anotados (Madrid, 1848), III, pp. 759-760.

${ }^{6}$ Real Pragmática de Carlos III de 31 de enero de 1768 [RP 1768], en SÁnCHEZ, Santos, Colección de pragmáticas, cédulas, provisiones, auto acordados y otras providencias generales, expedidas por el Consejo Real en el reynado del señor don Carlos IIP (Madrid, 1803), pp. 94-99.

${ }^{7}$ Part. 5, 13, 31, cit. (n. 5) p. 760. También Nov. Rec. 10, 24, 5. 
público, autenticada por funcionario competente (escribano), con tal que la primera fuere más antigua.

Ante este gran desorden, el diputado Mariano Elías Sánchez, promovió mediante moción presentada a la Cámara, un proyecto de ley con fecha 22 de agosto de 1842, el cual sostenía en su artículo $1^{\circ}$ lo siguiente ${ }^{8}$ : “Art. $1^{\circ}$. Quedan derogadas todas las leyes que conceden privilegios entre si a los documentos extendidos en papel sellado por el orden de fechas, o por el reconocimiento de las firmas, o por tener cláusula de hipoteca, o por estar escrito todo de puño i letra del deudor i en presencia de testigos; $i$ cuando los bienes de un concurso no alcanzaren para pagar integramente a todos los acreedores, siempre que estos hagan constar sus créditos en el papel sellado correspondiente, serán pagados a prorrata, después que lo hayan sido los acreedores escriturarios i demás a quienes las leyes conceden expresamente iguales privilegios".

Por su parte, el artículo $2^{\circ}$ disponía: "Art. $2^{\circ}$. La disposición contenida en el artículo anterior tendrá efecto quince días después de su publicación en la capital de cada provincia".

Este proyecto, que pretendió derogar todas esas leyes antiguas aludidas más atrás, tenía también como finalidad simplificar las disposiciones relativas a la graduación de acreedores personales en los concursos, proyecto que en definitiva fue informado favorablemente el 11 de agosto de 1843 por la Comisión de Legislación, pero formulado de una manera distinta": "Art. $1^{\circ}$. Los documentos privados extendidos en papel sellado correspondiente, cualquiera que sea su calidad, no alcanzando a ser cubierto integramente en los concursos, se pagarán sueldo a libra graduándose después de las escrituras públicas". Art. 2. "Quedan derogadas las leyes contrarias a la presente".

En la discusión de este proyecto, en sesión de fecha 4 de septiembre de 1843, el diputado Juan Manuel Cobo, formuló la siguiente indicación ${ }^{10}$ : “Art. $1^{\circ}$. Se deroga la lei 31, tit. 13, Part. $5^{a}$ en cuanto da fuerza de escritura i grado conforme a su antigüedad al documento hipotecario extendido privadamente por la mano misma del deudor i firmado por tres testigos. En su consecuencia tales documentos se reputarán por simplemente privados". Art. $2^{\circ}$. Se deroga igualmente la lei 5a, tit. 21 , lib. 10 de la Nov. Rec., en cuando manda graduar entre sí mismos conforme a su antelación los documentos privados extendidos en papel sellado. En su consecuencia, después de los créditos privilegiados por la lei y de los escriturarios, se pagarán sueldo a libra las obligaciones privadas otorgadas en papel del sello competente, cualesquiera que sean sus formalidades; i después de éstas, los demás créditos personales i quirografarios, que estén escritos en papel común o de sello incompetente, por un segundo rateo; siempre que los bienes del deudor común no bastaren para cubrir a todos en ambos casos". Art. $3^{\circ}$. La presente lei no tendrá aplicación sino sobre los documentos y obligaciones que se otorgaren pasados noventa dias de su publicación en un periódico oficial'.

Cualquiera que hubiere sido la motivación en estos proyectos, incompletos

\footnotetext{
${ }^{8}$ Palma, Alejo, Hipoteca especial en Chile, memoria Universidad de Chile, en Anales de la Universidad de Chile, 28/12 (Santiago, 1866), p. 855.

${ }^{9}$ Ibíd., p. 856. Firmaron este proyecto de ley los señores Pedro Francisco Lira, José Victorino Lastarria, y José Santiago Velásquez.

${ }^{10}$ Ibíd.
} 
por cierto, la realidad de los abusos por aplicación de la Partida V en cuestión, abrumaba al comercio y reclamaban una urgente y completa reforma. De hecho, algunos comerciantes de Valparaíso expusieron al Senado sobre la necesidad de discutir el proyecto de ley que seguía dormido en esa cámara y que pese a su discusión por los diputados, no estaba siendo despachada por el Senado.

La idea de los comerciantes era "aminorar los males que en dichos concursos [mercantiles] causan las disputas entre los acreedores" ${ }^{11}$. Firman esta solicitud Josué Waddington, Federhuth Gruningole, y José N. Sánchez. Ante la solicitud de los comerciantes de Valparaíso (y también de la capital), el Senado dispuso su discusión para la siguiente sesión, la cual se publicó en El Mercurio de Valparaíso, de 31 de agosto de 1844 (número 4906).

Luego, en sesión de fecha 25 de noviembre de 1844, el Senado, "habiendo tomado en consideración el proyecto de lei aprobado por esa honorable Cámara [de diputados] sobre preferencia de créditos en concurso de acreedores", vino en acordar el texto que en aquella oportunidad pasó a discutirse ${ }^{12}$.

Las bases estaban preparadas para operar el profundo cambio del sistema basado en la legislación española de las Ordenanzas de Bilbao, encaminándonos hacia el establecimiento de un régimen hipotecario que sólo quedará bien afianzado y definido, con la ley de prelación de créditos de 1854, y posteriormente, con el Código Civil y el Reglamento para la oficina del registro conservatorio de bienes raíces de 1857 .

\section{LEGISLACIÓN SOBRE PRELACIÓN DE CRÉDITOS (1845 y 1854)}

La ley general que reguló entonces la materia ya reseñada, se dictó con fecha 31 de octubre de 1845 sobre prelación de $\operatorname{créditos}^{13}$, siendo atribuida a la pluma de Andrés Bello (a la sazón ya parte de nuestra sociedad desde 1829). Con ella se vino a alterar la legislación de las Partidas de Alfonso X (aún vigente en Chile), pero no significativamente, como se puede apreciar de lo expresado en la ley, artículos 13 inciso final, 14 inciso $1^{\circ}, 15$ y 16, además de algunas intervenciones del venezolano ante el Congreso Nacional que así lo demuestran.

En efecto, en esas intervenciones, contenidas en el número 723 del periódico El Araucano, de fecha 28 de junio de $1844^{14}$, Bello señala claramente que el proyecto de ley a presentar en esa data, parte "del principio de que ninguna hipoteca pasa a tercero si no ha sido registrada $i$ anotada con especificación de la finca o fincas que le son afectas, principio que nos parece claramente enunciado en la legislación española que hoy rige, aunque algunos lo dudan, $i$ a que entendemos conforman sus

\footnotetext{
${ }^{11}$ Letelier, Valentín, cit. (n. 1), pp. 256 ss.

${ }^{12}$ Letelier, Valentín, Sesiones de los cuerpos legislativos de la república de Chile 1811-1845, Cámara de Diputados (Santiago, 1908), XXXIV, pp. 640-643.

${ }^{13}$ Ley de 31 de octubre de 1845 sobre prelación de créditos, en Boletín de Leyes 13/11 (Santiago, 1845), pp. 301-307. También AnguiTA, Ricardo, Leyes promulgadas en Chile desde 1810 hasta el $1^{\circ}$ de junio de 1913 (Santiago, 1912-18), II, pp. 470-473.

${ }^{14}$ Bello López, Andrés, Hipotecas i privilegios, en Opuisculos jurídicos, Obras Completas (Santiago, 1885), IX, pp. 411-415.
} 
decisiones las más altas autoridades judiciales de la República"15. Y continúa: "Sentado este principio, preguntamos: ¿no convendría dar a la hipoteca especial registrada la primacía sobre las generales? ${ }^{16}$

Resulta claro a estas alturas que para Bello siempre fue mejor reforzar la idea de una hipoteca especial registrada que dejar a su entero arbitrio aquellas creadas por la ley y no registradas en lugar alguno, como ocurría en la legislación española, aunque se tratara de normas protectoras.

En lo que nos concierne, el texto definitivo de esta ley dispuso la concreción del principio expuesto por Bello en su artículo del periódico El Araucano que no es otro que el de especialidad"17. Art. 13, inciso final: "La lei no reconoce más hipotecas generales que las creadas por ella". Art. 14, inciso $1^{\circ}$ : "La hipoteca general afecta todos los bienes presentes y futuros, pero no da derecho para perseguir los bienes del deudor que hubieren sido enajenados". Art. 15: [inc. 10] "La hipoteca especial no valdrá, sino fuere otorgada por escritura pública i registrada en la correspondiente oficina, dentro del término legal'. [inc. 20] La hipoteca especial da derecho para perseguir contra terceros poseedores los bienes raices hipotecados". Art. 16: "[inc. 10] Las hipotecas generales $i$ las especiales se considerarán como de un mismo grado, $i$ tendrán lugar indistintamente según el orden de sus fechas". [inc. 2०] Las hipotecas de igual fecha concurrirán a prorrata".

Esta ley además disminuyó las causas de preferencia sólo a tres: el privilegio, la hipoteca y la escritura pública. El principal mérito de la ley de 1845, según José Eugenio Vergara "consiste en haber puesto en claro derechos que antes eran oscuros i embrollados, en haber suprimido la hipoteca general convencional, que hacía tan inseguro el crédito de los particulares; $i$ sobre todo, en haber preparado el camino a reformas más extensas" 18 .

No obstante limitarse por la ley la constitución de hipotecas legales, éstas no accederían al registro, lo cual fue un retroceso en términos de publicidad.

${ }^{15}$ LeTELier, Valentín, cit. (n. 11), pp. 63-68.

${ }^{16}$ Ibíd.

${ }^{17}$ Pérez Fernández del Castillo, Bernardo, Derecho registral (Porrúa, 1990) pp. 71-114. El principio de especialidad o especialización es "aquel que tiene por finalidad determinar perfectamente los bienes objeto de inscripción, sus titulares, así como el alcance y contenido de los derechos". El principio de publicidad tiene una doble connotación: una material (relativa a los derechos que otorga la inscripción: presunción de su existencia y oponibilidad frente a terceros), y formal (relativa a la concesión por parte del registro público, de todas las certificaciones que permiten obtener una constancia de tales anotaciones o asientos). En tanto que el principio de inscripción es aquel por el cual "para que un asiento o anotación produzca sus efectos, debe constar en el folio real o en el libro correspondiente".

${ }^{18}$ Vergara Gáleas, José Eugenio, Discurso de incorporación a la Facultad de Leyes de la Universidad de Chile, en Anales de la Universidad de Chile (Santiago, 1853), pp. 80-95. También Tocornal, Enrique, Análisis comparado de nuestra legislación hipotecaria, en Anales de la Universidad de Chile, 19 (Santiago, 1861) pp. 766-856. 
Para los efectos de la prelación en concurso, ésta ley consideró de manera importante la especialidad, ordenando que la denominación de hipoteca especial se extendiese también a los censos y a las prendas constituidas por escritura pública (artículo 18): "Art. 18. Para los efectos de la prelación, la denominación de hipoteca especial se estiende a los censos, $i$ a las prendas constituidas por escritura pública".

A pesar del esfuerzo que se nota en la construcción de esta norma, se siguió dando preferencia tanto a hipotecas generales como a especiales, sin distinguir entre ellas, según la fecha de su otorgamiento, y concurriendo aquellas iguales en antigüedad, con lo que sufría la hipoteca especial una depresión notable cuando entraba en competencia con la general.

El número excesivo de privilegios y su preponderancia sobre la hipoteca desvirtuaron en gran manera los caracteres de que fue investida la especial. Así, según se señalaba en el artículo 21 , inciso $2^{\circ}$ de la ley, el crédito garantizado con hipoteca especial fue privado de los intereses cuando entraba en concurso, desde el día siguiente al de la formación del mismo.

La gran importancia de esta ley, sin embargo, no radica tanto en lo descrito respecto de las hipotecas y los privilegios, sino en la creación del primer registro propio (nacional) de hipotecas, censos y naves, mediante decreto supremo de fecha 20 de mayo de $1848^{19}$ (ordenado por el artículo 24 de la ley), norma que, entre otras cosas, fijó para el registro el término fatal de un mes, contado desde la data del otorgamiento de la escritura de la hipoteca o del censo (artículo $5^{\circ}$ del Reglamento).

De la misma manera, la norma en comento estableció nuevas oficinas anotadoras de hipotecas, en cada capital de departamento, a cargo de un escribano, por lo que se creó un oficio en aquellos puntos del país en que a la sazón no se hubiere establecido una oficina anotadora de hipotecas conforme a la antigua legislación española ${ }^{20}$ : Illapel el 20 de mayo de 1848; Rengo el 6 de julio de 1848; Parral el 22 de julio de 1848; Linares el 9 de agosto de 1848; San Carlos el 3 de noviembre de 1848; Putaendo el 3 de mayo de 1849; Valdivia el 3 de mayo de 1849; Chillán el 19 de octubre de 1849; Los Ángeles el 26 de noviembre de 1849; y, Petorca el 4 de mayo de 1853.

La ley de 1845, sin embargo, no logró suprimir los abusos e inconvenientes que traía consigo, como hemos visto, en relación con el escaso desarrollo de la publicidad y de la especialidad, como normas fundamentales de un sistema hipotecario moderno. Sí permitió el establecimiento de un modelo de registro que obligaba a los usuarios a registrar, dentro de un plazo perentorio -un mes-, sólo aquellas hipotecas especiales que constaren por escritura pública. La norma estableció de la misma forma que el registro de las hipotecas, censos y naves estuviere a cargo de un escribano público.

Como fuere, lo único que modificó la ley de 1845 fue lo concerniente a la prelación de créditos en concurso de acreedores, de modo que el registro sólo

${ }^{19}$ Reglamento sobre inscripción o registro de hipotecas y de censos, en Boletín de Leyes, 16 (Santiago, 1848), pp. 164-168.

${ }^{20}$ En 1858, todas las oficinas de hipotecas existentes en Chile se convirtieron en registros conservatorios. 
se refirió a las hipotecas especiales que constaren en escritura pública, regla que se extendió así mismo al censo. La idea era otorgar fecha cierta al acto más que ayudar a la constitución por inscripción de un derecho real a favor de quien accedía al registro.

No obstante reconocerse el principio de especialidad de la hipoteca, no se advierte la presencia de los principios de publicidad y de inscripción, también expuestos en la cita. Ello nos revela que las alusiones al registro, al menos en esta época, sólo están referidas a ese principio presente ya en la legislación española (Novísima Recopilación). Aunque esta posición irá evolucionando, conforme nos acerquemos al Código Civil y al Reglamento de 1857, la idea matriz de mantener el sistema español, seguirá siendo prioridad para el autor venezolano ${ }^{21}$.

Nos parece del todo atingente anotar que Bello estaba pensando en el sistema español que creó las Oficinas anotadoras de hipotecas o Contadurías de hipotecas, como también se les llamó ${ }^{22}$. El mismo provenía como sabemos de una Real Pragmática dictada por Pedro I en 1339, la cual estableció los cimientos del sistema que luego sería materializado en la Pragmática de Carlos III de enero de 1768, pasando el texto de ésta, en su integridad, a la Novísima Recopilación de $1805^{23}$.

También sabemos que Bello escribe en 1844 un discurso en el que fija su postura frente a la dicotomía entre hipotecas generales y especiales, que luego se materializará en la ley de 1845 . En ese trabajo, Bello iguala la condición de la hipoteca especial $\mathrm{r}$ e $\mathrm{g}$ is $\mathrm{t} \mathrm{r}$ a d a , frente a las hipotecas legales privilegiadas, y las hipotecas generales convencionales se equiparan a las especiales no registradas en un grado inferior a las especiales registradas ${ }^{24}$.

Pese al proyecto impulsado por Bello, los comerciantes de Valparaíso le hicieron ver nuevamente al gobierno, los inconvenientes de mantener una postura preferente respecto de las reglas sobre contratación mercantil, contenidas como se ha dicho en las Ordenanzas de Bilbao, plenamente vigentes en el Chile de la época ${ }^{25}$.

De hecho, en un artículo publicado en el periódico El Progreso, que data del 5 de julio de 1844, se hace alusión directa al proyecto de Bello sobre hipotecas y censos otrora publicado en El Araucano el 28 de junio de 1844, como ya indicamos. Dicho comentario, que refiere directamente a las mencionadas Ordenanzas y, además, a la ley de quiebras y bancarrota francesa de 28 de mayo de 1838 , se devela la misma opinión que refuerza la idea de un sistema que debía mantenerse (o seguirse, respectivamente) ${ }^{26}$. No es que los comerciantes de Valparaíso hayan

${ }^{21}$ Bravo LiRa, Bernardino, Una codificación parcial: las leyes de prelación de créditos de 1845 , 1854 y 1857 en Chile, en Revista Chilena de Derecho, 9 (Santiago, 1983) pp. 281-324.

${ }^{22} \mathrm{La}$ especialidad de la hipoteca es, como señala Bello, una cuestión ínsita en la legislación española que como sabemos proviene de los tiempos de Pedro I de Castilla, la que incorporada en las Partidas de Alfonso X, terminaron presentes en la Novísima Recopilación.

${ }^{23}$ Es cierto que la normativa antes ya se encontraba en las Partidas de Alfonso X, pero no como la encontramos en la Real Pragmática de 1768, sino que como se presentaba en la norma de Pedro I (1339).

${ }^{24}$ Bravo Lira, Bernardino, cit. (n. 21), p. 286.

${ }^{25}$ Ibíd.

${ }^{26}$ LeTELier, Valentín, cit. (n. 11), documento anexo n 45, pp. 66-67. 
cambiado de criterio, sino que el momento histórico es diverso, pues ya existe un claro avance en la ley de 1845 , como manifestamos ya al respecto. En efecto, la ley de 1845 constituye una evidente apología del sistema concursal en caso de quiebra, cuestión que preocupaba a los comerciantes sobre todo del puerto, los que eran muy persistentes en sus demandas al Gobierno y al Congreso, en todas las épocas anotadas (1840 a 1854). El problema de las hipotecas y del registro de inmuebles era, por lo tanto, de menor importancia para ellos.

El reglamento de esta ley y que desarrolla lo dispuesto en el artículo 24, fue promulgado el 20 de mayo de $1848^{27}$, como ya también hemos señalado. En efecto, el mencionado artículo 24 de la ley de 1845, disponía lo siguiente: "Se autoriza al Gobierno para dictar las reglas a que deba sujetarse la inscripción o registro de las hipotecas especiales de bienes raices o de naves i la inscripción de censos".

La influencia del sistema de anotación de hipotecas español contenido a estas alturas en la Novísima Recopilación es notoria, ya que de su sola lectura asoma el principio de especialidad hipotecaria al que Bello hacía alusión en su moción presentada al Congreso en 1844: "Art. $1^{\circ}$. En cada capital de departamento habrá una oficina a cargo de un escribano (que será designado por el Gobierno [...] en la cual se registren todas las hipotecas especiales de bienes raíces situados dentro de los limites del expresado departamento [...]".

$\mathrm{Y}$ con el sistema español, la concordancia es notable ${ }^{28}$ :

Reglamento de 1848:

“Art. 1". En cada capital de departamento habrá una oficina a cargo de un escribano (que será designado por el Gobierno [...] en la cual se registren todas las hipotecas especiales de bienes raices situados dentro de los limites del expresado departamento".

"[...] en la cual se registren todas las hipotecas especiales de bienes raices situados dentro de los limites del expresado departamento [...]".
Novísima:

"Establecimiento del Oficio de hipotecas en las cabezas de partido de todo el Reino, a cargo de los escribanos de Ayuntamiento".

"Será obligación de los Escribanos de Ayuntamiento de las cabezas de partido tener, ya sea en un libro o en muchos, registros separados de cada uno de los pueblos del distrito, con la inscripción correspondiente, y de modo que con distinción y claridad se tome la razón respectiva al pueblo en que estuvieren situadas las hipotecas".

El artículo $2^{\circ}$ del Reglamento dispone lo siguiente: "Los departamentos en que no se hubiere establecido hasta ahora ningún oficio de escribano público, harán [estos]

${ }^{27}$ LeTelier, Valentín, cit. (n. 1) pp. 164-168.

${ }^{28}$ Nov. Rec. 10, 15, 3. 
los registros de las hipotecas o censos que se constituyan sobre bienes situados dentro de su territorio, en la capital del departamento inmediato que el Gobierno designe, mientras no se establezca en ellos dicho oficio de escribano".

$\mathrm{Al}$ cabo de un tiempo, la inquietud de los comerciantes vuelve a hacerse patente, y Bello escribirá un dictamen o informe por encargo del entonces presidente Manuel Montt ${ }^{29}$, quien no contento con escuchar la opinión del jurista, le encarga la redacción de un proyecto de ley, que el Consejo de Estado somete a deliberación con fecha 17 de junio de 1852, aprobándolo con data 3 de julio, y remitiéndolo al Congreso el 31 de julio, ambas fechas de 1852. El 2 de agosto de 1852 el mismo aparecerá publicado en El Araucano, representando éste el antecedente directo de la ley de 1854 sobre prelación de créditos ${ }^{30}$.

Es en este proyecto de 1854 en el que finalmente se completa la enumeración de los privilegios reconocidos por la ley; se suprime la preferencia de que gozaban los créditos otorgados por escritura pública; $y$, se dispone la precedencia de las hipotecas especiales por sobre las generales, sólo cuando aquellas constaren por escritura pública.

A pesar de que el proyecto de Bello no sobrevive íntegro a la discusión parlamentaria, sí se observa que las ideas innovadoras del jurista relativas a la reducción de las causas de preferencia se mantuvo: el privilegio y la hipoteca; y, a la distinción clara entre hipotecas generales (legales o convencionales), y las especiales, prefiriéndose a estas últimas por sobre las primeras, y relegando a éstas a la cuarta clase, de modo que las especiales (fijadas en la tercera clase), le otorgaron a los acreedores mayores seguridades frente al concurso en el cual pudieren verse envueltas. Este sistema se mantuvo y sus normas pasaron al Código Civil, cambiándose sólo algunas denominaciones, como aquella relativa a la hipoteca legal ${ }^{31}$ : "Desde que entre nosotros, la hipoteca legal, ni impedia enajenar al deudor parte alguna de sus bienes, ni era dado perseguirla contra terceros poseedores, dejó de ser un peño y por consiguiente una hipoteca".

Y más adelante continúa: "Abolida esta prerrogativa por el citado artículo 15 (de la ley de 1854), la denominación era del todo impropia".

Por otra parte, la ley de 1854 , en su artículo $15, \mathrm{n}^{\circ} 3$, inciso $2^{\circ}$, disponía una cuestión relevante respecto de las hipotecas especiales: "La fecha de la hipoteca especial será la del día en que se hubiere efectuado el registro en la oficina de hipotecas; i quedan abolidas las leyes que fijan un término perentorio para dicha inscripción o registro, contado desde la fecha del instrumento", haciendo alusión en esta última parte al plazo de un mes que el Reglamento de 1848 había otorgado para inscribir a quienes constituían una hipoteca especial por escritura pública.

De esta manera, y dado que no existen normas específicas que se refieran al registro en la ley de 1854 (salvo en lo tocante a la derogación de la norma que establecía un plazo para inscribir de un mes), debemos colegir que el mecanismo español modificado, y contenido en el Reglamento de 1848, continuó vigente en

\footnotetext{
${ }^{29}$ De este dictamen sólo tenemos noticia por la cita que de él nos hace Bernardino Bravo Lira (ver nota 21).

${ }^{30}$ Bravo Lira, Bernardino, cit. (n. 21) p. 289.

${ }^{31}$ Ibíd., p. 293.
} 
cuanto al tratamiento de las hipotecas especiales y su registración, hasta la dictación en 1855 del Código Civil (artículo 695), y del Reglamento para la oficina del registro conservatorio de bienes raíces de 24 de junio de 1857.

Por último, debemos hacer presente que el Reglamento de 1848 vino por fin a derogar tácitamente (pues en él nada se dice al respecto), las normas de la Novísima Recopilación de 1805, y con ello, las de la Real Pragmática de Carlos III de 1768.

\section{ANÁLISIS DE LAS PRINCIPALES NORMAS CONTENIDAS EN EL RegLamento DE 1848}

Veamos a continuación, algunas de las normas contenidas en el Reglamento de 1848 que convierten a la misma en un antecedente relevante para la reconstrucción del registro inmobiliario chileno.

Primeramente, y en referencia a la naturaleza jurídica de esta pieza legislativa, diremos que la misma se contiene en un Decreto Supremo reglamentario, lo cual emana principalmente de la primera parte del mismo que utiliza la palabra 'decreto', de las expresiones 'comuníquese y publíquese' (tan propia de este tipo de normas), y la firma al final del mismo del presidente Manuel Bulnes y de su ministro de justicia, culto e instrucción, Salvador Sanfuentes. Algunos pensarán que se trata de un decreto con fuerza de ley, pero lo cierto es que aquello no acontece por el contenido eminentemente reglamentario que se la da al mismo en su redacción.

Este Reglamento contiene 16 artículos, ordenados bajo un solo rótulo: "Reglamento Sobre inscripción o rejistro de hipotecas i de censos".

El funcionario encargado de llevar el registro creado en virtud de la ley de 1845 , no tiene un nombre señalado en ninguna de sus normas. No obstante, ya en el artículo $1^{\circ}$ se habla de 'oficina a cargo de un escribano' de lo que entendemos que el funcionario a que aludimos era un escribano público; sin perjuicio de que en los artículos $4^{\circ}, 6^{\circ}, 9^{\circ}$ y $10^{\circ}$, se lea la expresión 'anotador', de huelga que el funcionario a cargo de esta oficina debemos llamarlo 'anotador de hipotecas y censos', o simplemente 'anotador'. Las funciones ejercidas por este sujeto son las mismas que las de los escribanos, como se puede apreciar del texto del mismo artículo $4^{\circ}$, cuando dice que el libro anotador "[...] se irá formando del mismo modo que los protocolos de los escribanos [...]".

El territorio de competencia del 'anotador' es el departamento, que es una división territorial que vino a remplazar lo que hasta ese entonces era un 'partido' ${ }^{32}$. Así, en la capital del departamento un escribano sería el encargado de llevar uno o más libros donde se registraran o inscribieran las hipotecas especiales sobre bienes raíces situados dentro de sus límites, con algunas normas especiales cuando el tamaño del inmueble abarcara más de un departamento, o cuando el bien estuviere dispuesto de tal forma que debiera hacerse el registro en cada uno de las oficinas correspondientes a ese territorio (artículos $1^{\circ}, 2^{\circ}, 3^{\circ}$ y $4^{\circ}$ ).

32 Sanhueza, María Carolina, La primera división político-administrativa de Chile, 1811 1826, en Revista Historia PUC 2 (Santiago, 2008), p. 453 ss. Rec. 5, 15, 1. Nov. Rec. 5, 16, 1, y 5, 16, 1, 3. RP 1768, 1. 
El plazo para realizar esta inscripción era de un $\mathrm{mes}^{33}$, término que finalmente fue suprimido por el artículo 15 de la ley de $1854^{34}$.

Respecto de la naturaleza y objeto del registro, éste era de oponibilidad y de publicidad de los contratos en los cuales se hubiere constituido hipoteca o censo, pues de no mediar este registro, tampoco se podía utilizar en juicio válidamente (artículos 15, 19 inciso final y 20 de la ley de 1845) ${ }^{35}$.

El título exhibido al anotador debía ser la primera copia del instrumento que otorgara el escribano público ${ }^{36}$, lo que se aviene con el actual principio de legalidad en su vertiente de titulación auténtica. Es decir, al registro no ingresaban instrumentos privados, o no escriturados, conforme a lo previsto en los artículos 19 y 20 de la ley de $1845^{37}$.

La inscripción se realizaba tomando razón del título exhibido al anotador en los términos que señalaba el artículo $8^{\circ}$ : “El rejistro o anotación consistirá en hacer referencia individual en el libro respectivo de los nombres $i$ apellidos del acreedor $i$ del deudor, de su vecindad, de la calidad del contrato u obligación, espresando el capital del censo, o el del crédito para cuya seguridad se establece la hipoteca, el interés o pensión, i la época o épocas en que debe hacerse el pago. Se mencionarán los bienes gravados que contiene el instrumento, con espresión de sus nombres, situación i linderos si fueren raices [...] en la misma forma que esprese el enunciado instrumento, la fecha de éste $i$ el escribano ante el cual se hubiere estendido" ${ }^{38}$. Se observa todavía una confusión entre inscribir, anotar y tomar razón, pues se trata de situaciones distintas. En el caso de la norma transcrita, pensamos que se acerca a lo que llamamos inscripción hoy en día. Respecto de las otras dos expresiones, nos parece que no tienen una connotación muy precisa, y seguramente aquello acontece porque la legislación española las utilizaba desde tiempos inmemoriales. En este sentido, la Real Pragmática de 1768 reduce la inscripción al acto de tomar razón al que se alude en

${ }^{33}$ En la $R P$ 1768, 2 la notación (ingreso) debía hacerse en el plazo de 24 horas o 3 días si el instrumento exhibido al anotador era antiguo, pero la toma de razón debía realizarse en el término de 6 días, RP 1768, 6. En la Novísima ese plazo es también de 6 días, Nov. Rec. 10, 16, 2.

${ }^{34} \mathrm{El}$ artículo 15 de la ley de 1854 , en su numeral $3^{\circ}$, inciso $2^{\circ}$, dispuso que: "La fecha de la hipoteca especial será la del día en que se hubiere efectuado el rejistro en la oficina de hipotecas; $i$ quedan abolidas las leyes que fijan un término perentorio para dicha inscripción o rejistro".

${ }^{35}$ Señalaba esta norma: "La hipoteca especial no valdrá si no fuere otorgada por escritura pública i registrada en la correspondiente oficina, dentro del término legal".

${ }^{36} \mathrm{El}$ artículo $6^{\circ}$ del Reglamento señalaba: "[...] Este título será la primera copia que diera el escribano [...]".

${ }^{37}$ Disponía el artículo 20 de la ley de 1845: "No se entenderá por escritura pública sino la otorgada ante escribano o quien legalmente haga sus veces, i debidamente protocolizada”. Se requería lo mismo en Nov. Rec. 10, 16, 3, 3; y, en RP 1768, 3.

${ }^{38}$ Lo mismo en Nov. Rec. 10, 16, 3, 4: "La toma de razón ha de estar reducida a referir la data o fecha de instrumento, los nombres de los otorgantes, su vecindad, la calidad del contrato, obligación ofundación; diciendo si es imposición, venta, fianza, vinculo u otro gravamen de esta clase, y los bienes raices gravados o hipotecados que contiene el instrumento, con expresión de sus nombres, cabidas, situación y linderos en la misma forma que se exprese en el instrumento: y se previene, que por bienes raices, además de casas, heredades y otros de esta calidad inherentes al suelo, se entienden también los censos, oficios y otros derechos perpetuos que puedan admitir gravamen, o constituir hipotecas". También RP 1768, 4. 
su numeral $4^{\circ}$, lo cual hay que relacionar con lo previsto en la Novísima (Nov. Rec. 10, 16, 3, 4) que disponía: "La toma de razón ha de estar reducida a [...]". El Reglamento de 1848 , por su parte, habla en el citado artículo $8^{\circ}$, de 'el rejistro o anotación', como si ambas expresiones fueren sinónimas. Pensamos que tomar razón y anotar van por caminos diversos que inscribir y que registrar ${ }^{39}$, pero que tanto en la Real Pragmática de 1768 como en la Novísima, el uso de ese vocablo (i n s c r i b i r), se acerca más a lo que actualmente se entiende por tal. De hecho, anotar ha sobrevivido a tomar razón en lo que se denomina 'anotación preventiva' en el Reglamento de 1857.

Ejecutado el rejistro, como señala el artículo $9^{\circ}$ del Reglamento de 1848, el anotador debe poner una nota (o sea, anotar), lo siguiente: "Se rejistró en la oficina de hipotecas del departamento tal, al folio tantos, bajo tal número, el día de hoi"; concluyendo la nota con la fecha y firma del anotador, devolviendo el título al interesado con esa certificación ${ }^{40}$.

En cuanto a la publicidad formal del registro, el artículo 14 disponía que cualquier interesado podía pedir al anotador el apunte extrajudicial de las hipotecas y censos, ya simplemente, ya con certificación autorizada, esto es, entregando al interesado copia autorizada por el funcionario sin necesidad de una resolución judicial $^{41}$.

Por último, los artículos 15 y 16 se refieren al arancel que podían cobrar los anotadores de hipotecas, aspecto que también se cuidaba en la Real Pragmática de 1768 y en la Novísima ${ }^{42}$.

Es precisamente en esta parte, donde se puede advertir el influjo que tuvo este Reglamento de 1848 en el que será el actual Reglamento para la oficina del registro conservatorio de bienes raíces de 1857 . En efecto, en cuanto a la inscripción, el cambio desde la toma de razón hacia la inscripción constitutiva es paradigmático, pues una simple anotación es remplazada por un acto más complejo y completo que vino a dar forma al principio de especialidad, cuyo contenido es apreciable en los artículos 8 y 9 del Reglamento de 1848 y los artículos 78 y 81 del Reglamento de 1857, como se puede evidenciar de la comparativa:

${ }^{39}$ Registrar hay que entenderlo como todo acto que implique acceso al registro. De esta manera, resulta ser un concepto genérico. No así la inscripción que es un acto mucho más específico. La anotación es también más específica; en tanto que tomar razón quedó relegada al olvido, siendo rescatado quizás por el derecho administrativo. Véase el artículo 11 del Reglamento, que utiliza las tres expresiones como si fueren sinónimas.

${ }^{40}$ Nov. Rec. 10, 16, 3, 5. RP 1768, 5.

${ }^{41}$ Nov. Rec. 10, 16, 3, 7. RP 1768, 7.

${ }^{42}$ Nov. Rec. 10, 16, 3, 9. RP 1768, 9. 
Art. 8 Reglamento de 1848:

“El rejistro o anotación consistirá en hacer referencia individual en el libro respectivo de los nombres $i$ apellidos del acreddor $i$ del deudor, de su vecindad, de la calidad del contrato u obligación, espresando el capital del censo, o del crédito para cuya seguridad se establece la hipoteca, el interés o pensión, i la época o épocas en que debe hacerse el pago. Se mencionarán los bienes gravados que contiene el instrumento, con espresión de sus nombres, situación y linderos si fuesen raices, o de sus nombres, clase, arqueo $i$ número con que estuviesen matriculados, si fueren naves, en la misma forma que esprese el enunciado instrumento, la fecha de éste i el escribano ante el cual se hubiere estendido".

Art. 9 Reglamento de 1848:

"Ejecutado el rejistro, el anotador pondrá al pie del instrumento original exhibido, la nota siguiente: Se rejistró en la oficina de hipotecas del departamento tal, al folio tantos, bajo tal número, el dia de hoy; $i$ concluyendo con la fecha, la firmará, i devolverá el instrumento al interesado, a fin de que, si este quisiere, lo exhiba al escribano orijinario ante quien se otorgó, $i$ le haga anotar en el protocolo estar registrado en la oficina correspondiente, espresando la fecha de esta anotación".
Art. 78 Reglamento de 1857:

"La inscripción de títulos de propiedad i de derechos reales, contendrá:

1. ${ }^{\circ}$ La fecha de la inscripción;

2. ${ }^{\circ}$ La naturaleza, fecha del titulo $i$ oficina en que se guarda el orijinal;

3. ${ }^{\circ}$ Los nombres, apellidos $i$ domicilios de las partes;

$4 .^{\circ}$ El nombre $i$ linderos del fundo;

5. 'La firma del Conservador".

Artículos 86 y 87 Reglamento de 1857:

Art. 86. "El título se devolverá con nota de haberse inscripto, del rejistro, numero i fecha de la inscripción, la fecha de la nota i la firma del Conservador" (inc. $1^{\circ}$ ).

Art. 87. "El interesado, si quiere, podrá ocurrir con la copia ante el Escribano orijinario, quien será obligado a trasladar la nota al marjen de la escritura matriz".

Como se puede apreciar, existe una evidente evolución en cuanto al contenido de las inscripciones, lo que da cuenta a nuestro entender de un influjo al menos nimio entre ambas legislaciones. Ahora bien, ello no quiere decir que ambas normas hayan tenido un antepasado común, pues el Reglamento de 1848 es evolución patria de la Pragmática de Carlos III de 1768; en cambio, el Reglamento de 1857, es una norma cuyas fuentes son más amplias que la norma real, pues se trata de una variada mezcla de legislaciones europeas que a la sazón estuvieron presentes en textos de origen francés e italiano, que a su turno, derivan de otras legislaciones vigentes en la época, como es del caso del propio Code de 1804, los códigos de 
los reinos italianos de principios del siglo XIX, y germanos, como el prusiano de 1794, o el austriaco de 1811.

Por ello, pensamos que el Reglamento de 1848 es fuente de algunas normas del Reglamento de 1857, pero en su justa medida, pues como hemos visto, la evolución presente en el segundo, es mayor y más rica normativamente hablando que la del anterior.

\section{Conclusiones}

Sin lugar a dudas, el Reglamento de 20 de mayo de 1848 constituye una pieza de gran importancia en el desarrollo del registro inmobiliario en nuestro país, ya que se trata de la primera norma propiamente chilena que regula con algún detalle un sistema hipotecario a partir del concurso de acreedores acaecido en una quiebra. O sea, la idea de crearlo nunca fue la de establecer un sistema de registro constitutivo de las hipotecas y menos del dominio sobre bienes raíces.

De hecho, la técnica utilizada es la misma de la Novísima (y por ende de la Real Pragmática de 1768), esto es, por medio de una rudimentaria inscripción que consistía en anotar o tomar razón de las hipotecas especiales contenidas en instrumentos públicos (escrituras públicas), a fin de ser oponibles válidamente a terceros en los mencionados juicios de quiebra en que hubiere concurso de acreedores.

El hecho de legislar acerca de la prelación de créditos en un concurso de acreedores dio pie a la instalación en Chile de una forma de registro rudimentario que homologaba la legislación española sobre hipotecas, censos y naves, ya existente en España desde 1768 en la Real Pragmática de Carlos III, y luego en la Novísima Recopilación de Leyes de España de 1805. Es una decisión que se emparenta con lo que Bello pensaba de la legislación española, en cuanto a mantener lo mejor de ella, adaptándola y desechando aquellas normas que no se adecuaran a nuestra realidad.

De paso no sólo logra el objetivo de sacarse de encima a los comerciantes de Valparaíso, sino que ensayar un modelo propio de registro de las hipotecas especiales. No olvidemos que los comerciantes de Valparaíso deseaban un sistema hipotecario que solucionara los problemas relativos a la quiebra, dejando de aplicar las Ordenanzas de Bilbao que databan de 1737.

En lo relativo a las normas del Código de Comercio francés de 1807, del Código de Comercio español de 1829, y de la ley de quiebras francesa de 1838, no fue necesario aplicarlas debido a la decisión de Bello de establecer el sistema de registración ya contenido en la Novísima.

La ley de 1845 cumple de manera contundente e innovadora con lo perseguido por los grupos de presión, pues reduce las causas de preferencia a sólo tres, dándole importancia preponderante a la hipoteca especial que conste de escritura pública, por sobre la general, sea ésta convencional o legal, creando de paso un sistema nacional de registro que, aunque basado en la legislación española y relativo a hipotecas, censos y naves, tuvo el mérito de conciliar las fuerzas políticas y económicas, respondiendo a un imperativo de la época: rechazar todo lo que fuere de origen hispano; todo un acierto que es digno de encomio y que ha sido analizado en el presente trabajo. 


\section{BiBLIOGRAFÍA}

\section{Fuentes}

Code de Commerce français I (Paris, 1807).

Código de Comercio español (Madrid, 1829).

Las Siete Partidas de Alfonso X, en Los códigos españoles concordados y anotados (Madrid, 1848), III.

Ley de 31 de octubre de 1845 sobre prelación de créditos, en Boletín de Leyes, 13/11 (Santiago, 1845), pp. 301-307.

Ordenanzas del Consulado de Bilbao, en Los códigos españoles (Madrid, 1851), XII.

Reglamento sobre inscripción o registro de hipotecas y de censos, en Boletín de Leyes, 16 (Santiago, 1848), pp. 164-168.

Reglamento de registro conservatorio de bienes raices, en Boletín de Leyes, 25 (Santiago, 1857), pp. 128-149.

2. Literatura

Anguita, Ricardo, Leyes promulgadas en Chile desde 1810 hasta el $1^{\circ}$ de junio de 1913 (Santiago, 1912-18), II.

Bello Lopez, Andrés, Hipotecas i privilegios, en Opúsculos jurídicos, Obras Completas (Santiago, 1885), IX, pp. 411-415.

Bravo LiRa, Bernardino, Una codificación parcial: las leyes de prelación de créditos de 1845, 1854 y 1857 en Chile, en Revista Chilena de Derecho, 9 (Santiago, 1983), pp. 281-324.

Carbonell O'Brien, Esteban, Banca y suspensión de pagos. Mecanismos alternativos de reingeniería legal (Lima, 2007).

LETELIER, Valentín, Sesiones de los cuerpos legislativos de la república de Chile 1811-1845,

Cámara de Senadores (Santiago, 1908), XXXV.

LETELIER, Valentín, Sesiones de los cuerpos legislativos de la república de Chile 1811-1845,

Cámara de Diputados (Santiago, 1908), XXXIV.

Palma, Alejo, Hipoteca especial en Chile, memoria Universidad de Chile, en Anales de la Universidad de Chile, 28/12 (Santiago, 1866), pp. 849-864.

Pérez Fernández del Castillo, Bernardo, Derecho registral (Porrúa, 1990).

SÁNCHEZ, Santos, Colección de pragmáticas, cédulas, provisiones, auto acordados y otras providencias generales, expedidas por el Consejo Real en el reynado del señor don Carlos IIP (Madrid, 1803).

SAnHuEZA, María Carolina, La primera división politico-administrativa de Chile, 18111826, en Revista Historia, 41/2 (Santiago, 2008), pp. 447-493.

Tocornal, Enrique, Análisis comparado de nuestra legislación hipotecaria, en Anales de la Universidad de Chile, 19 (Santiago, 1861), pp. 766-856.

Vergara Gáleas, José Eugenio, Discurso de incorporación a la Facultad de Leyes de la Universidad de Chile, en Anales de la Universidad de Chile (Santiago, 1853), pp. 80-95. 